\title{
Proposing a Framework for Understanding the Diffusion of Technology: The Case of Laser Technology
}

\author{
David E. Desplaces \\ College of Charleston \\ Steven W. Congden \\ University of Hartford \\ Fred J. Wergeles \\ University of Hartford
}

A framework for studying the diffusion process of laser-based cutting and welding technologies to small precision manufacturing companies is proposed. A preliminary multi-case study of small businesses highlights factors impacting the laser-based precision manufacturing industry in Connecticut and underscores the importance of studying diffusion as a multi-stage, continuous, and dynamic process that reflects the various needs of these small businesses to remain competitive. It calls for facilitating the sharing of information and resources among technology and manufacturing companies to ensure their long-term competitiveness in an increasingly dynamic overall environment.

Keywords: Diffusion, Technology, Aerospace, Competitiveness

\section{INTRODUCTION}

The transition to next generation technology as it relates to supply chain competitiveness in the Aerospace Industry has become the focus of congressional and executive mandates. Specifically, the National Aerospace Leadership Initiative (NALI) was created in 2004 to respond to the critical needs of the U.S. aerospace manufacturing supply chain. The goal was to maintain worldwide leadership in advanced propulsion and power systems, as well as to preserve and develop a culture of innovation in the highly competitive domestic aerospace manufacturing supplier base in an effort to meet the Department of Defense's current and future needs. In particular, NALI was designed to develop regional industrial capabilities central to the aerospace industry.

In general, this research addresses NALI's need to maintain an innovative and competitive domestic aerospace supplier base by looking at how technology initiatives are managed and diffused. Research into the management of technology has traditionally focused on the science, innovation, and R\&D associated with strategic development of technology initiatives (Chen, 2005). Attention has been directed mainly to large corporate $\mathrm{R} \& \mathrm{D}$ and product development initiatives while largely ignoring the issues of small 
businesses adopting and applying next generation technologies. We attempt to close this gap in the literature by focusing this study on small businesses in the laser-based precision manufacturing industry.

It is becoming more generally accepted that the process of diffusion and application of technology provides a positive impact on industry competitiveness (Dornblaser, Lin, \& Van de Ven, 2000). Consequently, understanding the diffusion and adoption of technology is crucial in assessing how University-based activities can support and enhance laser-applications in support of NALI. Understanding the factors and the roles each plays in determining the rate, pattern, and extent of the diffusion of laser technology across potential adopters will allow us to develop a more robust, best-practice model for small businesses and identify the role that any facilitating agents or organizations could provide. Prior research from the innovation literature has characterized technological innovation as a means for changing industry characteristics (Christensen, 1997). These characteristics include building effective barriers to entry and shaping the overall industry infrastructure. They have also been associated with building competitive market power and organization structure. The goal of this research is to identify the issues and factors associated with the innovation diffusion/adoption process of laser technology by employing an established analytical framework developed by Everett Rogers (2003) to a sample of three small Connecticut based companies in the laser-based precision manufacturing industry. Next, we describe the framework of our research based on a review of the literature.

\section{LITERATURE}

The complexity of the competitive forces small businesses face has grown tenfold with the increased introduction of competence destroying technologies. As technology increasingly becomes multidisciplinary and dynamic in nature, small businesses are reacting by instituting strategic technology initiatives to assist in decreasing product cycle times, limiting exposure to competitive pressures, and increasing firm survival (Arvanitis \& Vonortas, 2000; Steensma \& Corley, 2000).

In general, technology is often defined as the physical manifestation of new products and processes (Chen 2005). While this definition of technology is widely accepted in the literature, this represents a rather narrow view of technology. As such, we have adopted a more robust characterization of technology by also including the intangible technological know-how associated with products and processes. Therefore, we define technology as the physical manifestation of technological know-how associated with both products and processes.

In the context of this study, technology initiative refers to the diffusion process, including the formal adoption and use of a new technology by a given small business (Stoneman \& Diederen, 1994). While "new" is often used to describe both an incremental or radical evolution to a given technology, Cantamasa, Montagna, and Cascini (2016) define "new" not just from the technological point of view, but that it also makes business sense. As such, we apply the term from a firm specific perspective as an appropriate competitive tool. What might be considered a new technology initiative to one company may represent a completed technology initiative for another.

Researchers in the management of innovation and technology areas have long been concerned with issues related to the diffusion of technology (Berenson, 1968; Kindra \& Goyal, 1983; Loch \& Huberman, 1999; Veugelers \& Cassiman, 2004). The emphasis has been on the diffusion, or rather, the rate of adoption by firms of radical technologies including both processes and products (Loch \& Huberman, 1999; Chen, 2005). These studies have focused more on extreme paradigm shifts by identifying competence destroying radical technologies. However, along with short periods of radical change, industries are also generally characterized by a large number of incremental innovations. While this area of study has assisted in understanding these phenomena, it has focused on a marginally low occurrence event while largely ignoring the relative nature of new technology that is firm specific.

Early studies by Gatignon and Robertson (1989) presented a conceptual model of technology adoption that examined the effects of the competitive environment, organizational characteristics, and decision maker information processing on adoption rates. While this model advanced understanding of technology diffusion, the focus was clearly on the competitive environment and largely ignored the 
multidimensional nature of the technology diffusion process. Furthermore, the study focused on the context of consumer product development within the field of marketing.

Studies have also examined policy issues (Veugelers \& Cassiman, 2004), intra-organizational technology diffusion (Chen, 1983), technology characteristics (Vanden, 2003), innovation cycles (Sharp \& Miller, 2016), actor influence modeling (Cantamessa, Montagna, \& Cascini, 2016), standardization (Blind, 2016), and market competitiveness (Chen, 2005), among many. While these studies have contributed to our understanding of the diffusion process and some of the factors associated with the successful diffusion and adoption of technology, they focused largely on technology diffusion within large multidivisional organizations with an emphasis on internal technology diffusion. Furthermore, these studies have largely ignored time as an important dimension of the diffusion and adoption of technology process. Rogers (2003) describes technology adoption as a diffusion process by which an innovation is communicated through certain channels over time among the members of a social system that emphasizes innovation, time (stages), communication channels, and the social system (decision making).

While prior research has contributed to our current understanding, there are significant challenges. We address these challenges and contribute to the current gap by proposing a comprehensive multidimensional model for studying the technology diffusion process among a set of small businesses. Specifically, we build on the work of Everett Rogers (2003) and examine the technology diffusion process from a hierarchical multidimensional staged approach, while applying several interacting factors that have been identified as critical to technology diffusion in the literature. Using existing literature on diffusion process modeling (Schroeder, Van de Ven, Scudder, \& Polley, 2000), we present a new conceptual model (Figure 1) of the technology diffusion process that is both temporal and dynamic in nature, and which gives diffusion over time more emphasis than has previous research.

\section{FIGURE 1}

\section{TECHNOLOGY DIFFUSION MODEL}

\section{Diffusion Stage:}

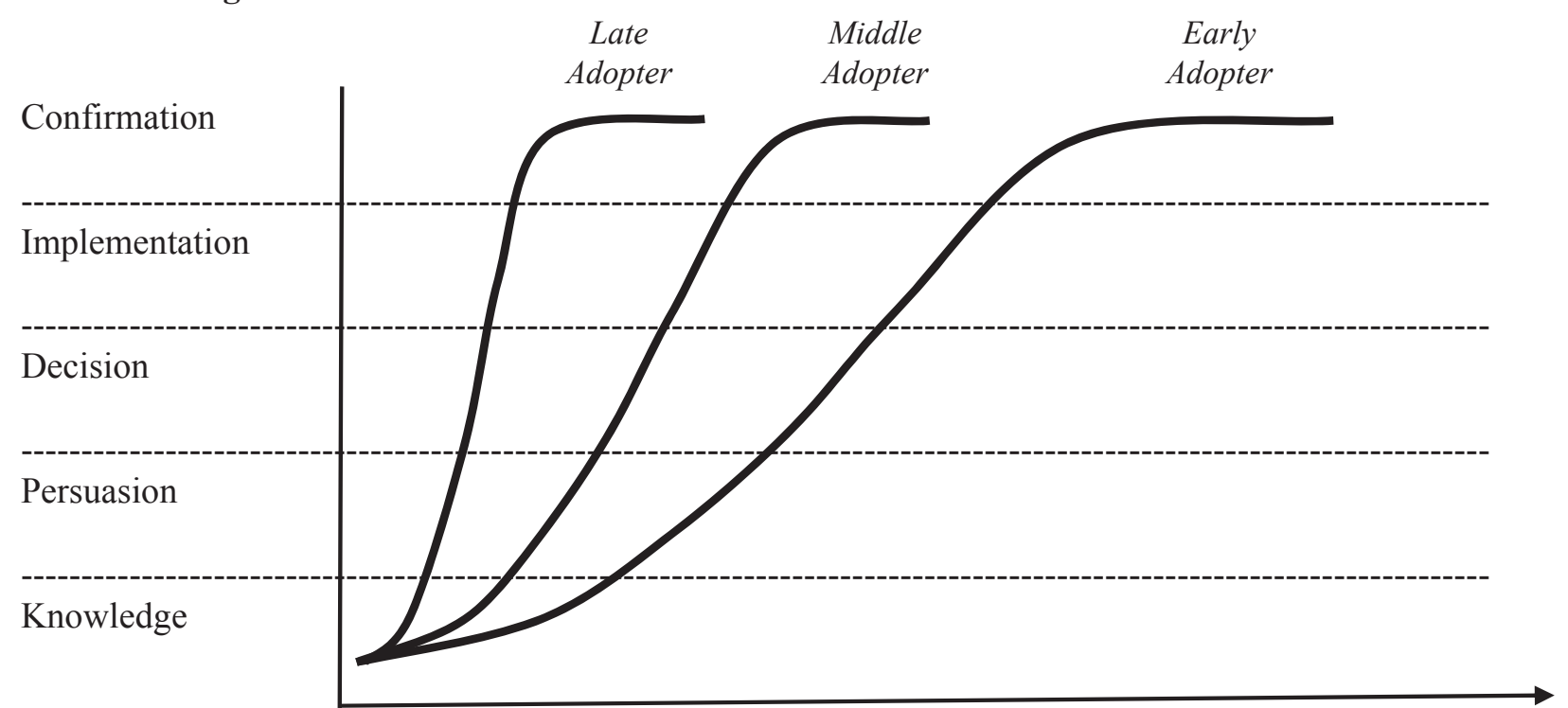

Time 0

\begin{tabular}{|l}
\hline Diffusion Factors: \\
- Standardization of Technology \\
- Technology Characteristics \\
- Communication Channels \\
- Management Type \\
- Corkforce \\
\hline
\end{tabular}

Time X 
We outline below the stages for the technology diffusion trajectory, followed by an outline of the interacting factors identified in the literature to influence the diffusion process over time.

\section{Technology Diffusion Trajectory}

Building on the seminal work of Everett Rogers (2003), we have adopted a hierarchical multi-stage approach to the technology adoption decision process as follows:

\section{Knowledge Stage}

When an organizational unit is made aware of the existence of an innovation and gains the understanding of each of the usable functions of the innovation. This might include the creation of needs, which is a state of dissatisfaction with the status quo.

\section{Persuasion Stage}

When the organizational unit forms a favorable or unfavorable attitude towards the innovation. Because all innovations carry some degree of uncertainty, innovation-evaluation information might be sought and used by different members of the organization or by members that can influence that organizational unit.

\section{Decision Stage}

When the organizational unit engages in activities that lead to a choice being made about the innovation. These activities could include trials, free samples to clients, or demonstrations. During this stage the organizational unit makes an adoption or rejection decision.

\section{Implementation Stage}

When the organizational unit puts an innovation into use. This can include complete or partial implementation (an approach used to reduce uncertainty).

\section{Confirmation Stage}

When the organizational unit seeks reinforcement of the innovation-decision or possibly reverses earlier decisions. At the individual level, this stage attempts to avoid or reduce dissonance.

\section{Interacting Diffusion Factors}

A comprehensive review of existing literature related to the diffusion of new technologies (speed to market) in the context of public to private technology initiatives have been identified as follows:

\section{Standardization of Technology}

Several studies indicate the standardization of a technology as a significant component to the diffusion process. That is, to what extent the technology is explicit or implicit. The extent the technological know-how is codifiable is an important component of the process (Walter, 2000). Gatignon and Robertson (1986) argued that standardization of technology is positively associated with rapid technology diffusion. Chen (2005), and Nyberg, Moliterno, Hale Jr, and Lepak (2012), argued for integration between a firm's technology strategy and human resources management. Chen (2005) specifically argued that a firm should focus on the effort to convert tacit technical know-how into codifiable technical know-how for the purpose of ease of knowledge transfer. Technology diffusion can be dependent on the access to knowledge and, therefore, the more standardized the know-how, the greater the access to the know-how for the diffusion process.

\section{Technology Characteristics}

Several studies of technology characteristics have identified the conceptualization of radical versus incremental technology to characterize the technology diffusion initiative. However, critics of this line of thinking have presented arguments suggesting this simple dichotomy of technology characteristics fails to 
capture the true nature of technology. Historians of technology have argued that the role of external factors often interacts with the diffusion of technology (Loch \& Huberman, 1999). As such, the notion of uncertainty related to the success of technology initiatives is a critical component of the characteristics of technology. Therefore, the conceptualization of technology characteristics is multidimensional rather than dichotomous in nature. It includes the radicalness of technology, the extent to which the technology or technical know-how can be replicated by other firms in the industry, and the inherent uncertainty related to the application of the technology. Building off the work by Steensma and Corley (2000), we have adopted a multidimensional characterization of technology that includes uniqueness, imitability, and uncertainty.

\section{Communication Channels}

Social network theorists have identified several benefits of network relationships. The central position of this research has focused on the benefit of information that is accessible to network participants. Burt (1997) argued that weak network benefits provide participants with access to significant non-redundant sources of information. On the other hand, Coleman and Rippin (2000) argued that closed networks with strong partner ties based on high levels of trust provide information benefits and resources that are only available to actors within the network. As such, we include the extent to which the relationship between partners is strong or weak as a factor that will impact a firm's access to valuable information benefits related to technical know-how. There are benefits to both closed and bridged networks and therefore both types have been identified as important factors (Burt, 1997; Coleman \& Rippin, 2000).

\section{Management Type}

Several studies in the area of management style and organizational culture have identified the notion of entrepreneurial initiatives as those that are more likely to enhance an organization's innovativeness (Santoro \& Gopalakrishnan, 2001). Technology transfer has long been associated with organizational attributes including management structure. Successful initiatives must integrate technology with cultural awareness. Management must promote an organizational culture that supports the technology initiative and improves organizational access to necessary technical know-how (Chen 2005).

\section{Workforce}

Organizational resources have been identified as important to the overall productivity of a firm. In the case of technology adoption, human resources are a critical concern for the implementation of technology initiatives. The extent to which this resource contains the absorptive capacity to execute organizational initiatives should be a significant factor (Smith, 2001).

\section{Cost}

Finally, the profit maximization of an organization will require a firm to consider the return on investment throughout the lifecycle of the diffusion and adoption process (Steensma \& Corley, 2000). Return on investment has long been associated with firm performance in the management literature.

In conclusion, the objective of this research is to provide a robust and comprehensive analysis of the technology diffusion process by extending our current understanding with respect to the relationships identified and outlined above. In the following section we provide the fundamental foundation for the research methodology including rationale and sample/data considerations.

\section{RESEARCH METHODOLOGY}

Considering the high level of specialization of the industry and the preliminary nature of the research, we adopted a case-based approach allowing for the gathering of a rich and insightful data set. The case research approach is often cited for its high applicability to learning (Kazdin, 1982; Lundberg, Rainsford, Shay, \& Young, 2001) and also for the richness of its qualitative nature (Merriam, 1998; Schroeder et al., 
2000; Yin, 2003). It has often been applied when researching innovation phenomena (Van de Ven, Angle, \& Poole, 2000).

\section{The Process}

We followed the case research process suggested by Naumes and Naumes (2012). The process included conducting unstructured interviews with executives and key solution developers at the respective small businesses. Using our framework based on Rogers' work (2003) and leading open-ended questions, participants were given the opportunity to visualize the factors that might have influenced the diffusion process. The researchers used a facilitated-mapping approach that included identifying the factors and posting them on a large sheet of paper to display potential links across stages.

\section{Our Sample}

Employing the Small Business Administration's definition of small business based on size and volume, a total of 28 small businesses employing less than 500 employees were identified using multiple resources (Connecticut Center for Advance Technology, trade magazines, and various on-line sources). The researchers sent a letter to each CEO or technology director describing the purpose and intents of the research. Follow-up phone calls were made in an attempt to seek participation in this study. Due to the high level of competition and sensitive nature of the industry (aerospace), a limited number of companies showed interest in participating even after significant confidentiality and disguising guarantees were provided. The following are three cases studies (Companies X, Y and Z) that agreed to participate (see Figure 2).

FIGURE 2

\section{CASE STUDY RESULTS}

\section{Diffusion Stage:}

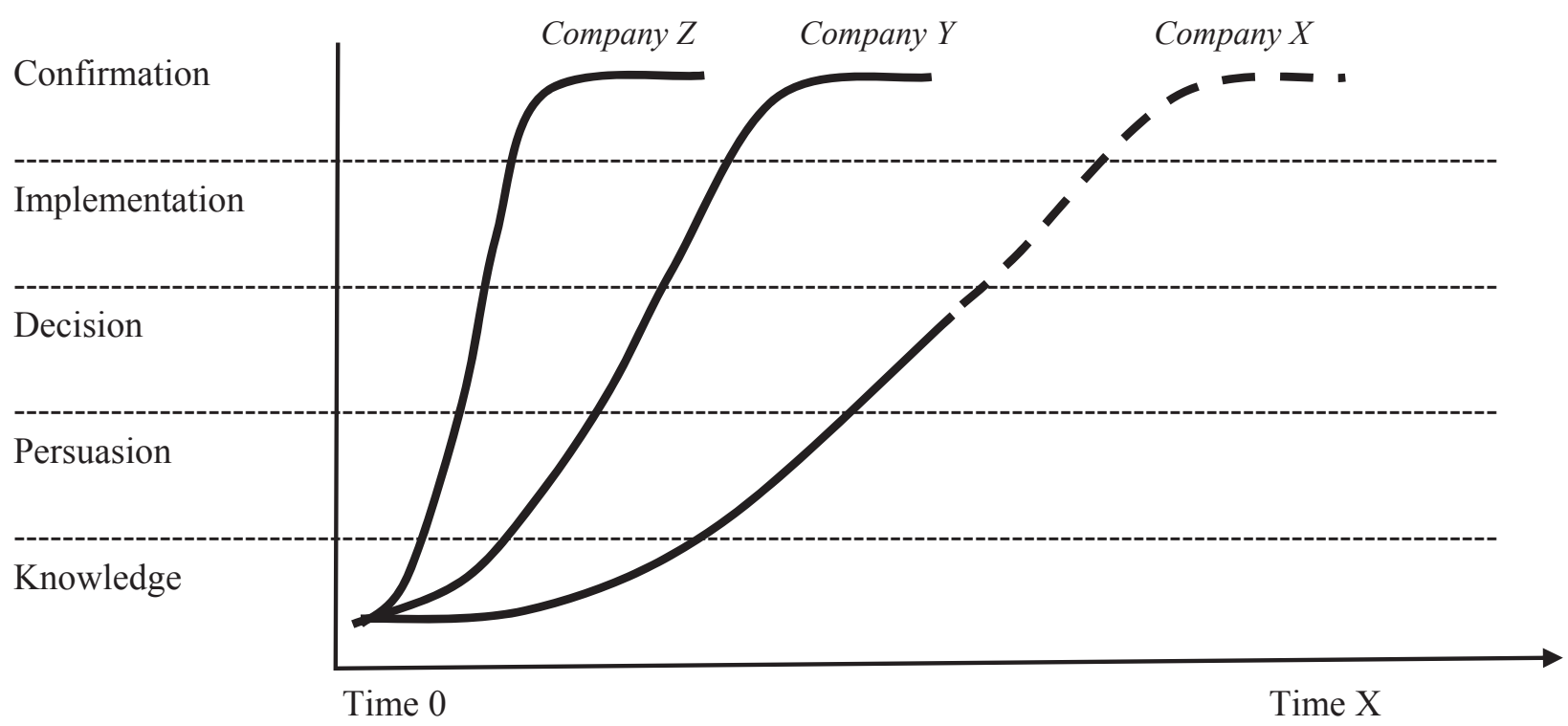

\section{Case 1 - Company $\mathrm{X}$}

The first case describes Company $\mathrm{X}$, which was uniquely positioned because of its long-standing links and relationships with the aerospace industry in Connecticut. Company $\mathrm{X}$ did not use laser technology at the time of this research but had considered and reviewed this technology on multiple occasions since its early existence. The latest diffusion/adoption process initiated by Company X, in which it assessed, evaluated and ultimately decided that laser-based technology would not benefit its 
strategic vision and long run needs, is reviewed below. While this case reveals important issues regarding a do-not-adopt outcome, the early evaluation of the technology by Company $\mathrm{X}$ can be seen as having the characteristics of an early adopter.

\section{Knowledge Stage}

In the knowledge stage, the Company $\mathrm{X}$ was made aware of the relevance that laser technology capabilities would have to precision manufacturing, especially to the aerospace industry the company had been serving for many years. Accordingly, it monitored industry trends carefully. However, specific review of the technology was more directly triggered by an annual technology competition sponsored by one of the laser manufacturing industry leaders. This presented Company $\mathrm{X}$ with a unique adoption opportunity consisting of competing for grants to study the feasibility of adopting the technology. This process signaled for Company $\mathrm{X}$ growing industry interest in the technology and the push for broad applications of the technology including aerospace supply chain effectiveness.

\section{Persuasion Stage}

Through this stage, the company reviewed its relationships with existing customers such as aerospace leaders, government, and national labs. Although historically cost was not considered a factor by these primary clients, the clients were now seeking next generation manufacturing processes with guaranteed superior quality that were also a cost-effective part of lean manufacturing.

\section{Decision Phase}

Management grew wary of the switching costs of using laser technology over what it considered a robust and established alternative technology. Although laser technology was perceived to be more desirable because of its novelty and high technology implications, an internal rate of return and development assessment that took into account training, union or personnel issues, management, and new equipment needs, became the primary persuading factor. Ultimately, the decision was made not to adopt laser technology because of perceived lower profitability mostly related to maintenance and workforce issues. The simplicity and reliability of the established technology were the comparison factors that allowed the current technology used by the company to prevail over adopting laser technology.

\section{Implementation and Confirmation Phases}

This phase did not materialize, but the company believed that the capital intensity (low margins) and high maintenance issues reported by the industry validated their decision.

\section{Case 2 - Company Y}

The second case describes the process employed by a manufacturer using both lasers and electron beam welding techniques for their customers primarily in the aerospace and medical device industries. Over the past few years, Company Y had invested in state-of-the art welding machines, along with a sizable investment in personnel resources. Their goal was to be the leading high-end design engineering and welding manufacturing company in the region. A few years prior, they had the opportunity to incorporate a new laser-welding device into their facility. The following is a description of the process they used to evaluate and adopt the technology.

\section{Knowledge Stage}

Company Y learned about the new technology from a laser device manufacturer (Company W). Company Y used both business and technical criteria to evaluate the opportunity to add a state-of-the-art laser-welding device to their facility. The business criteria included price, efficiency of operations (labor costs, operational space), maintenance costs, and the flexibility the device could add to the solutions Company Y provided to its customers. The technical criteria included the maturity of the technology, the potential impact of integrating a new device into their facility (e.g., downtime), and the means to integrate the technology into their proprietary manufacturing processes. 


\section{Persuasion Stage}

During this phase, Company Y used a team approach to evaluate the opportunity. The team assessed the technical capabilities of the new device compared with their existing suite of manufacturing devices. They also evaluated the impact on employee training and retention, and considered how much effort would be required for feasibility testing. All of this was conducted in conjunction with discussions with Company Y's customers to determine their needs and whether the new device could provide better performance outcomes to the customer.

\section{Decision Phase}

After the evaluation of the device in the first two stages, a primary factor in accepting the device hinged on the long-established relationship Company Y had with the device manufacturer. They also based the decision on the determination that the technology was stable and posed a small risk of failure to deliver on its claimed specifications. They also evaluated potential markets and customers to determine the need and acceptability of the new technology.

\section{Implementation Phase}

During implementation, Company $\mathrm{Y}$ faced a number of challenges in further developing opportunities for the new device. There was a competition with existing endeavors for personnel, equipment, and other materials. The time and effort spent on fully developing and exploiting the new device's capabilities took away from the resources spent on the day-to-day manufacturing operations for existing customers. Company Y personnel explained that they would like to explore all the interesting capabilities more but would end up having to come in on weekends or very early in the morning in order not to disrupt the current operations that paid the bills.

\section{Confirmation Phase}

During this phase, Company Y continued to evaluate the performance of the new device using the business and technical criteria established early in the decision process. The company was confident of success as they continued to look for new market and customer opportunities to use the new device. Company $\mathrm{Y}$ also continued to monitor both production and quality metrics to ensure the new device delivered exceptional performance for their customers.

\section{Case 3 - Company $Z$}

The third case in the series examining the diffusion/adoption of technology was a small welding and cutting manufacturer that had embraced the latest in laser process and manufacturing technologies. While Company $\mathrm{Z}$ had a long history in the cutting and welding industry, most recently, they had completed a technology initiative that greatly increased their overall capabilities. In doing so, they had been able to extend their previous customer base. They provided services in both the aerospace and defense industries. Following is their laser technology initiative examined in greater detail.

\section{Knowledge Stage}

In the knowledge stage, Company $\mathrm{Z}$ drew from many sources of both technical capability and manufacturing process information. These sources included both informal and formal network resources such as current customer relationships, print publications, trade associations, and manufacturers for process automation \& laser application. While the knowledge available indicated there were a considerable amount of benefits (quality, flexibility, efficiency) associated with the stand-alone technology applications, the main criteria developed in the knowledge stage pertained to the application of multiple technologies as a seamless integration and automation process throughout the enterprise.

\section{Persuasion Stage}

In the persuasion phase, Company $\mathrm{Z}$ used the information gathered in the previous stage for a more robust analysis of the feasibility of such a large endeavor. This phase included a formal cost-benefit 
analysis along with an analysis of potential physical resource limitations (land, labor, and capital). While the analyses conducted were formal in context, the company used a team approach for developing a request for proposal and demonstrations from their technology suppliers. Finally, the primary outcome of this stage indicated that the growth forecast of Company $\mathrm{Z}$ was not sustainable under their current resource stock. The company discovered based on their research and information gathering efforts that they were falling behind their competitors in the application and use of laser manufacturing technology. The indication was that Company $\mathrm{Z}$ was 2-3 years delayed in adopting laser manufacturing technologies. This realization had a significant impact on the decision stage.

\section{Decision Phase}

In this stage, the feasibility of the application of an integrated manufacturing cell became the primary focus. Company $\mathrm{Z}$ examined the final decision criteria based on their previous analyses. With the implications of falling further behind their competitors in mind, Company $\mathrm{Z}$ focused on the feasibility of purchasing and financing an integrated manufacturing cell. Furthermore, they focused on factors such as standardization, technology integration, service and repair, and workforce training.

\section{Implementation Phase}

The implementation of the technology initiative presented some challenges. In this phase, Company $\mathrm{Z}$ worked closely with their technology suppliers to develop and integrate the manufacturing process. This included a significant investment and the setup of a new larger facility that employed a more efficient manufacturing process. This phase also presented significant software integration issues that lasted approximately 6 months and were solved working closely with their technology suppliers. While Company $\mathrm{Z}$ did have their share of technology issues, the long but successful implementation was largely credited to their strong network relationships. This included both strong ties with their technology suppliers and geographic proximity.

\section{Confirmation Phase}

While Company $\mathrm{Z}$ represented a relatively new technology adoption, they had some initial confirmation from the technology initiative. First, confirmation came from increased repeat business associated with their existing customers. This included both previously completed contracts and new orders based on their increased capabilities. Second, the increased capabilities led to increases of new customers in the areas of aerospace and defense, which prior to the technology initiative were not readily accessible. Finally, Company $\mathrm{Z}$ was able to extend its new capabilities in laser manufacturing applications by providing value added engineering services to resolve customer inquiries regarding cutting and welding applications.

\section{KEY FINDINGS}

Next, we identify patterns across the three participating small businesses as they apply to our proposed framework.

\section{Knowledge Phase}

All companies actively monitored the industry through both formal and informal means. Traditional formal networks like trade associations and publications offered limited opportunities, while informal networks like suppliers, customers relationships in various precision manufacturing industries (e.g. medical devices, computer, hardware, automotive, aerospace, and defense) were noticeably key facilitators. 


\section{Persuasion Phase}

Similarities across companies included production, maintenance and training cost, ease of use, programmability, quality, precision, and automation capabilities driven by customer needs. These factors are consistent with the reviewed literature on technology diffusion.

\section{Decision Phase}

Switching cost was the key driver in the adoption decision. The decision can be broken down into two basic areas, namely technology related issues and cost-benefit analysis. Technology related issues included stability, integration, reliability including laser supplier pre-purchase testing, ease of use, and workforce related elements. The cost-benefit factors included risk assessments, return on investments, and evaluation of potential markets. The company that opted not to adopt the technology reported that simplicity and reliability emerged as deciding factors against the adoption, specifically that the technology required an increase in maintenance and work force training.

\section{Implementation Phase}

The earlier adopter, Company Y, was seeking opportunities to explore the potential of the technology while the later adopter, Company $\mathrm{Z}$, faced challenges with respect to software and hardware integration typical of a turnkey view of the technology. The later company was solely focused on the promise made by the laser manufacturer to deliver a complete working application. Company $\mathrm{Y}$ was more entrepreneurial through their quests for discoveries than was Company $\mathrm{Z}$.

\section{Confirmation Phase}

The companies using the technology sought constant evaluation of the performance of the various applications from adoption. This included increased quality and reduced production time. A foreseeable increase in sales revenues from both current and prospective customers in a variety of industries, most notably aerospace and defense, was seen as validation of their decision to adopt the technology.

\section{Industry Implications}

Three points have emerged with respect to facilitating the diffusion of technologies in support of companies like X, Y, and Z. The recommendations that are offered are mutually dependent. Therefore, the impact of these points on the myriad of small businesses typical of the precision manufacturing industry must be considered as a multi-stage, continuous and dynamic process that mirrors the various needs outlined above.

\section{Facilitate the Rapid Diffusion of Technology in Regional Companies}

This study highlights the complexity of the diffusion process and the importance of facilitating the rapid diffusion of laser technology in order for states like Connecticut to remain competitive. Because most companies are small with limited resources for business analysis, a central clearing house of information and resources designed to support the industry with specific mandates should be established. It should assist companies in the process of evaluating alternative technologies with respect to current and future needs in an effort to expedite the adoption decision. Part of this process should be to monitor customer needs across the aerospace industry and disseminate this information to companies in the region. Work on regional entrepreneurial ecosystems (Engel, 2015) might mark a starting point to understanding the actors facilitating the diffusion process.

\section{Showcase and Promote Manufacturing Companies in the Region to Potential Customers in the Aerospace Industry}

We recommend a shift in approach from demand push by regional companies to demand-pull from customers. Manufacturers of laser technologies must work to showcase the technology as the future of next generation precision manufacturing with wide application to new market opportunities. While a lack of trust among companies and facilitating parties is a concern, facilitators can assist by: (1) providing 
opportunities such as one-day showcases for the region's best-in-class manufacturing and technology companies to demonstrate their capabilities and facilities; and (2) sponsoring technical symposia to facilitate the diffusion of non-proprietary technology and manufacturing techniques to assist new entrants in the field.

\section{Continue to Monitor the Aerospace Industry to Identify New Opportunities for the Region's Manufacturers}

The facilitating organization should conduct a thorough and ongoing strategic analysis by gathering competitive intelligence about the industry, its potential customers, and competing companies from other regions. This information could help the region's manufacturers decide the best path of technology adoption and refine their business plans and marketing efforts. Tightly coupled with such information is the need to continue to provide research grants to regional businesses and university labs to facilitate the rapid diffusion of state-of-the-art technologies and manufacturing techniques with the goal of promoting collaboration among universities, industry, and regions. Finally, it is important to partner with other organizations (U.S. and worldwide) to support the development of technologies.

\section{RESEARCH LIMITATIONS}

The impact of the study was limited by a narrow response rate likely due to a low climate of cooperation and trust by area companies competing for the same markets. In addition, the research was limited to a small number of specialty companies. The proposed framework should be applied to other industries to confirm validity and applicability.

\section{CONCLUSION}

This research identifies the above points as critical success factors associated with the diffusion of laser technology and the strengthening of the nation's aerospace supplier base as mandated by the NALI initiative. The implementation of these recommendations will uniquely position innovation centers and other supporting facilitators in bridging the stages of the diffusion process; from knowledge, persuasion, and decision, to the physical manifestation of the implementation and confirmation stages. This role underlies the suggested recommendations and is considered a unique contribution to this and future diffusion of technology initiatives. This is particularly important to the small business community and the development of a strong laser-based precision manufacturing industry. 


\section{REFERENCES}

Arvanitis, R., \& Vonortas, N.S. (2000). Technology transfer and learning through strategic technical alliances - International experiences: Introduction to the symposium. Journal of Technology Transfer, 25(1), 9-12.

Berenson, C. (1968). The R\&D: Marketing interface - A general analogue model for technology diffusion. Journal of Marketing, 32(2), 8-15.

Blind, K. (2016). The impact of standardisation and standards on innovation. In J. Edler, P. Cunningham, A. Gök, \& P. Shapira (Eds.), Handbook of Innovation Policy Impact (pp. 423-449). Cheltenham, Gloucestershire, UK: Edward Elgar Publishing.

Burt, R. S. (1997). A note on social capital and network content. Social Networks, 19(4), 355-373.

Cantamessa, M., Montagna, F., \& Cascini, G. (2016). Design for innovation-A methodology to engineer the innovation diffusion into the development process. Computers in Industry, 75(1), 46-57.

Chen, C. C. (2005). The effect of investment in technology diffusion within a firm on market competitiveness. International Journal of Management, 22(1), 142-153.

Chen, E. K. Y. (1983). Multinational corporations and technology diffusion in Hong Kong manufacturing. Applied Economics, 15, 309-321.

Christensen, C. M. (1997), The innovator's dilemma: When new technologies cause great firms to fail. Boston, MA: Harvard Business School Press.

Coleman, G., \& Rippin, R. (2000). Putting feminist theory to work: Collaboration as a means towards organizational change. Organizations, 7(4), 573-587.

Dornblaser, B. M., Lin, T., \& Van de Ven, A. H. (2000). Innovation outcomes, learning and action loops. In A. H. Van de Ven, H. L Angle \& M. S. Poole (Eds.), Research on the management of innovation: The Minnesota studies (pp. 193-217). Oxford, UK: Oxford University Press.

Engel, J.S. (2015). Global clusters of innovation: Lessons from Silicon Valley. California Management Review, 57(2), 36-65.

Gatignon, H., \& Robertson, T. S. (1989). Technology diffusion: An empirical test of competitive effects. Journal of Marketing, 53(1), 35-49.

Kazdin, A. E. (1982). Single case research designs: Methods for clinical and applied settings. Oxford, UK: Oxford University Press.

Kindra, G. S., \& Goyal, S. K. (1983). A case study of a model of technology diffusion in less developed countries. International Journal of Product Research, 21(4), 489-497.

Loch, C. H., \& Huberman, B. A. (1999). A punctuated-equilibrium model of technology diffusion. Management Science, 45(2), 160 - 177.

Lundberg, C. C., Rainsford, P., Shay, J. P., \& Young, C. A. (2001). Case writing reconsidered. Journal of Management Education, 25(4), 450-463.

Merriam, S. B. (1998). Case study research in education: A qualitative approach. San Francisco, CA: Jossey-Bass.

Naumes, W., \& Naumes, M. J. (2012). The Art and Craft of Case Writing. New York: Routledge.

Nyberg, A. J., Moliterno, T. P., Hale Jr, D., \& Lepak, D. P. (2012). Resource-based perspectives on unitlevel human capital: A review and integration. Journal of Management, 40(1), 316-346.

Rogers, E. M. (2003). Diffusion of innovations ( $5^{\text {th }}$ ed.). New York, NY: The Free Press.

Santoro, M. D., \& Gopalakrishnan, S. (2001). Relationship dynamics between university research centers and industrial firms: Their impact on technology transfer activities. Journal of Technology Transfer, 26(1-2), 163-171.

Schroeder, R. G., Van de Ven, A. H., Scudder, G. D., \& Polley, D. (2000). The development of innovation ideas. In A. H. Van de Ven, H. L Angle \& M. S. Poole (Eds.), Research on the management of innovation: The Minnesota studies (pp. 107-134). Oxford, UK: Oxford University Press.

50 American Journal of Management Vol. 19(4) 2019 
Sharp, B. E., \& Miller, S. A. (2016). Potential for integrating diffusion of innovation principles into life cycle assessment of emerging technologies. Environmental Science \& Technology, 50(6), 27712781.

Smith, E. A. (2001). The role of tacit and explicit knowledge in the workplace. Journal of Knowledge Management, 5(4), 311-321.

Steensma, H. K., \& Corley, K. G. (2000). On the performance of technology-sourcing partnerships: The interaction between partner interdependence and technology attributes. Academy of Management Journal, 43(6), 1045-1067.

Stoneman, P., \& Diederen, P. (1994). Technology diffusion and public policy. The Economic Journal, 104(425), 918-930.

Van de Ven, A. H., Angle, H. L., \& Poole, M. S. (2000). Research on the management of innovation: The Minnesota studies. Oxford, UK: Oxford University Press.

Vanden, K. F. (2003). Management structure and technology diffusion in Chinese state-owned enterprises. Energy Policy, 31(3), 247-257.

Veugelers, R., \& Cassiman, B. (2004). Foreign subsidiaries as a channel of international technology diffusion: Some direct firm level evidence from Belgium. European Economic Review, 48(2), 455-476.

Walter, J. (2000), Technological adaptation and "learning by cooperation." A case study of a successful onshore technology transfer in Tierra del Fuego. Journal of Technology Transfer, 25(1), 13-22.

Yin, R. K. (2003). Case study research: Design and methods ( $3^{\text {rd }}$ ed.). Thousand Oaks, CA: Sage Publications. 